\title{
Prognostic significance of Epstein-Barr virus infection in gastric cancer: a meta-analysis
}

\author{
Xuechao Liu ${ }^{1,2+}$, Jianjun Liu ${ }^{1,2 \dagger}$, Haibo Qiu ${ }^{1,2}$, Pengfei Kong ${ }^{1,2}$, Shangxiang Chen ${ }^{1,2}$, Wei Li ${ }^{1,2}$, Youqing Zhan ${ }^{1,2}$, \\ Yuanfang $\mathrm{Li}^{1,2}$, Yingbo Chen ${ }^{1,2}$, Zhiwei Zhou ${ }^{1,2}$, Dazhi $\mathrm{Xu}^{1,2^{*}}$ and Xiaowei Sun ${ }^{1,2^{*}}$
}

\begin{abstract}
Background: The prognostic significance of Epstein-Barr virus (EBV) infection in gastric cancer (GC) remains unclear. Recently, a number of studies have investigated the association between EBV infection and the prognosis of GC with controversial results. We therefore conducted a meta-analysis to assess its prognostic significance.

Methods: PubMed and EMBASE were searched for studies up to October 1, 2014. We investigated the association between EBV infection with survival in patients with GC. The pooled hazard ratio (HR) and its $95 \%$ confidence interval $(\mathrm{Cl})$ were calculated to evaluate risk.

Results: A final analysis of 8,336 patients with GC from 24 studies was performed. Our analysis results indicated that the pooled HR was 0.67 ( $95 \% \mathrm{Cl}: 0.55-0.79 ; Z=11.18, P<0.001$ ). Subgroup analyses stratified by region revealed that the protective role of EBV infection only remained in the Asian population (HR: $0.62,95 \%$ Cl: $0.48-0.75 ; P<0.001$ ). When stratified by study quality and statistical methodology, the protective role could also be identified in high quality studies (HR: 0.67, $95 \%$ Cl: 0.55-0.79) and in univariate analysis studies (HR: 0.62, $95 \%$ Cl: 0.50-0.74). There was no evidence of significant heterogeneity and publication bias.

Conclusions: The presence of EBV has a favorable impact on GC patient's survival, especially in an Asian population. Future updated studies, especially large-scale randomized controlled studies stratified by region, are warranted as validation studies.
\end{abstract}

Keywords: Gastric cancer, Epstein-Barr virus, Prognosis, Meta-analysis

\section{Background}

Gastric cancer (GC), one of the most common malignant tumors in the digestive tract, is the fourth most commonly diagnosed cancer and the second leading cause of cancer-related mortality worldwide [1]. Although the etiology of GC is still ambiguous, infectious agents have increasingly attracted attention as the mechanism of neoplastic transformation [2]. As we all know, Helicobacter pylori $(H$. pylori) is the major causative agent of GC [3]. Another infectious agent, Epstein-Barr virus (EBV) has also been found to be associated with GC [4-6]. EBV is a ubiquitous $\gamma$-herpes virus, which is grouped as a member of the herpesviridae family, subfamily gamma-Herpesvirinae, genus lymphocryptovirus

\footnotetext{
* Correspondence: xudzh@sysucc.org.cn; sunxw@sysucc.org.cn

${ }^{+}$Equal contributors

'State Key Laboratory of Oncology in South China, Collaborative Innovation Center for Cancer Medicine, Guangzhou, China

Full list of author information is available at the end of the article
}

$[7,8]$. Since its discovery in tumor cells of Burkitt's lymphoma in 1964 [9], EBV has been detected in a range of cancers, such as lymphoid neoplasms, nasopharyngeal, and gastric epithelial malignancies [10]. EBV-associated gastric carcinoma (EBVaGC) is defined by the presence of EBV in the GC cells, which represents about $9 \%$ of GC worldwide [11-14]. Therefore, EBVaGC is identified as a distinct disease entity consisting of lymphoepitheliomalike carcinoma (LELC) and conventional adenocarcinoma $[6,15]$. Though LELC has been reported to present a relatively favorable prognosis [16], the prognostic significance of EBVaGC is still controversial. A recent large-scale study from Huang $\mathrm{SC}$ et al. revealed no difference in survival between the EBVaGC cases and the EBV-negative cases [17]. Genitsch $\mathrm{V}$ et al. reported that there was no significant survival advantage for EBVaGC overall [18]. In addition, $\mathrm{He} \mathrm{Y}$ et al. also drew consistent conclusion [19]. Considering that a pooled analysis including 13 studies revealed a 
protective role for EBV infection in the prognosis of GC [20], we conducted an extensive search for articles that evaluated the association between EBV and the outcome of GC. Here, a meta-analysis was performed to more precisely estimate the association between EBV infection and the prognosis of GC.

\section{Methods}

\section{Search strategy and selection criteria}

Two electronic databases (i.e., PubMed and EMBASE) were searched to explore studies (published before 1 October, 2014) that investigated the prognostic significance of EBV infection on the prognosis of GC. There were no geographic or language restrictions. Medical Subject Headings $(\mathrm{MeSH})$ words used were the following keywords "Epstein-Barr virus", "stomach neoplasms", "gastric cancer", "gastric carcinoma", "prognosis" and "survival". We examined the authors' names and affiliations carefully to avoid duplicate data or overlapping articles. Abstracts of articles $(n=535)$ were checked independently by two investigators (XCL and JJL) to determine if full text articles should be obtained (Fig. 1), and disagreements were resolved by discussion with our research team.

Studies were eligible if survival was analyzed in GC patients stratified by EBV status. The primary outcome of interest was overall survival (OS). The meta-analysis was based on OS at 3 or 5 years that was extracted from published papers or original patient's data. OS was defined as the time from GC diagnosis to death or last follow-up. The eligibility criteria of the studies were as follows: to present a proven diagnosis of GC in patients; to provide a sensitive and reliable method for detection of the existent status of EBV; to evaluate the correlation between EBV status and patients' OS; to report a hazard ratio (HR) and $95 \%$ confidence interval (CI) or sufficient date to estimate the $\mathrm{HR}$ and $95 \% \mathrm{CI}$ according to methods previously described by Parmar et al. [21, 22].

\section{Data extraction}

Data were extracted by two investigators (XCL and JJL) independently using a predefined form. Discrepancies were resolved by discussion within our research team. The following data items were recorded from each study: first author, year of publication, time of follow-up, region, number of patients with positive and negative tumors, method of detection, positive rate, results of univariate and multivariate survival analyses, HRs and $95 \%$ CIs. If the relevant information was unavailable in the articles, we emailed the corresponding author for additional data.

\section{Quality assessment}

Study quality was assessed independently by two researchers (XCL and PFK) with the Newcastle-Ottawa quality assessment scale (Additional file 1: Table S1).
Disagreement was resolved by discussion within our research team. Each study was assessed on three main categories: selection, comparability and outcome. The Newcastle-Ottawa Scale (NOS) scores ranged from 0 to 9; and a score $\geq 6$ indicated good quality. As this was a metaanalysis, we did not include any humans and/or animals. Our study was approved by the Research Ethics Committee at the Cancer Center of Sun Yat-sen University.

\section{Statistical analysis}

Our research adhered to the Preferred Reporting Items for Systematic Reviews and Meta-Analyses (PRISMA) guidelines (Additional file 2: Table S2) [23, 24]. The effect of EBV infection on OS was measured by HR and the corresponding $95 \%$ CI. If the $95 \%$ CI for the pooled HR did not overlap 1, the effect was considered as statistically significant. At first, a fixed-effects model (the inverse variance method) was used for calculating pooled HRs. When significant heterogeneity was detected across studies, a random-effects model (DerSimonian and Laird method) was selected. The existence of heterogeneity between studies was assessed using the Cochrane $\mathrm{Q}$ test and $\mathrm{I}^{2}$ statistic; with $\mathrm{P}_{\mathrm{Q}}<0.05$ and $\mathrm{I}^{2}>50 \%$ considered to represent substantial heterogeneity between studies [25].

The HR of each study was estimated by various published methods $[21,22]$. The most accurate method was to retrieve the $\mathrm{HR}$ and $95 \% \mathrm{CI}$ from the reported results. When the study did not report the $95 \% \mathrm{CI}$, it was calculated by its P-value or O-E statistic (difference between numbers of observed and expected events). If the study only provided OS curves for the two groups, the HR estimate and its $95 \% \mathrm{CI}$ were reconstructed by extracting survival rates at specified times. In addition, there were three studies that only provided a risk ratio (RR) to evaluate the correlation between EBV status and patient OS rates. We selected the studies for further analysis with caution.

Publication bias was evaluated using a funnel plot, Begg's test and Egger's test. An asymmetric plot suggested possible publication bias. A two-sided $\mathrm{p}$ value $<0.05$ was considered statistically significant for the Begg's test and Egger's test $[26,27]$. Kaplan-Meier curves were read by Engauge Digitizer version 4.1 (http://digitizer.sourceforge.net). Statistical analysis was carried out using Stata software (version 12.0). All $\mathrm{P}$ values were two-sided and the significance level was 0.05 .

\section{Results}

\section{Study selection and characteristics}

A total of 535 articles were identified from two electronic databases, of which 24 studies were included for the metaanalysis in accordance with the selection criteria (Fig. 1) $[16,17,19,20,28-48]$. The positive rate of EBV varied from $2.02 \%$ [35] to $33.3 \%$ [36] and the overall EBV positivity was $9.3 \%$. Among these studies, 13 studies 


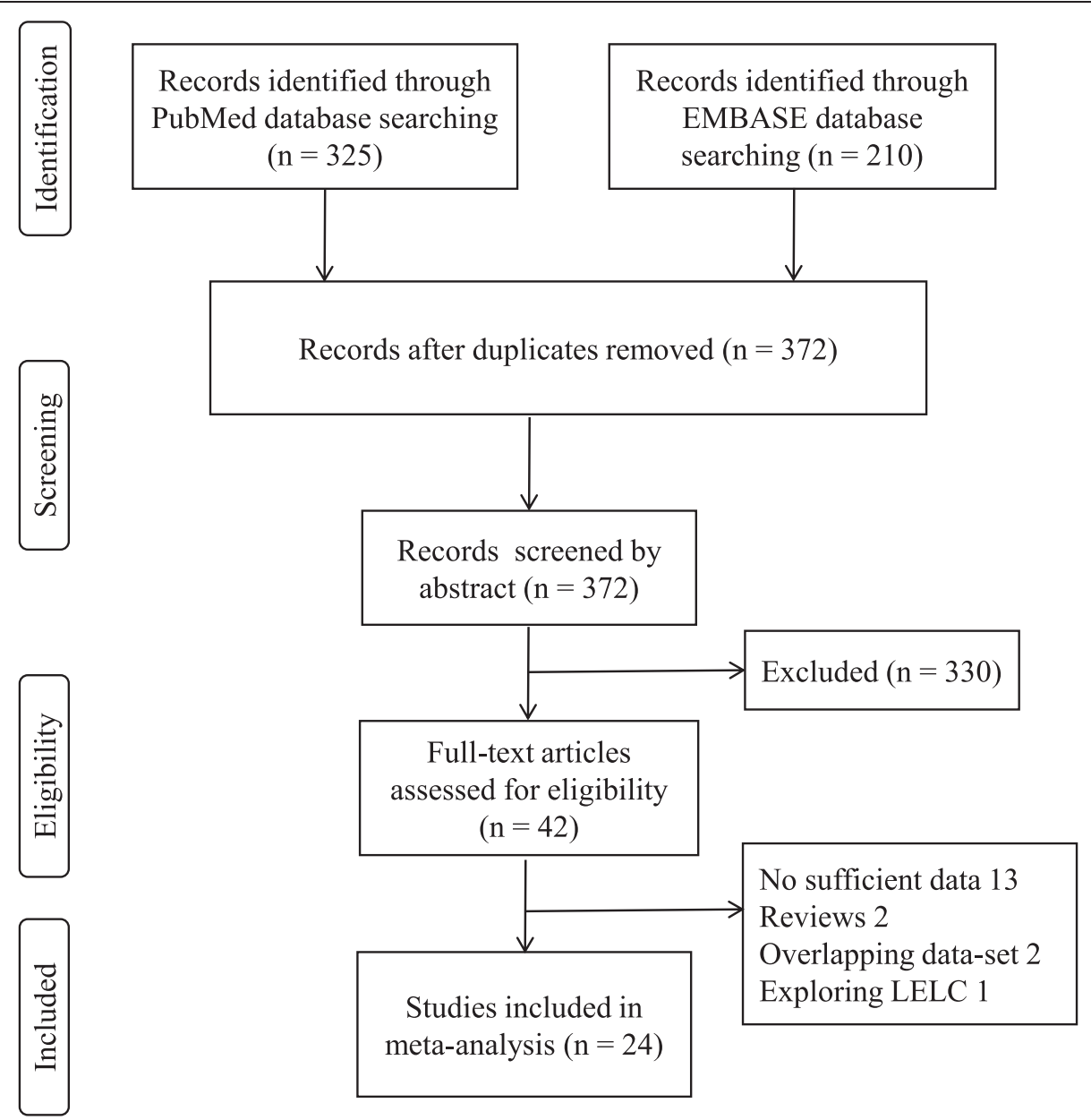

Fig. 1 Flow chart of articles selection for meta-analysis. Abbreviations: LELC, lymphoepithelioma-like carcinoma

were performed in Asian patients [17, 19, 28-38], five studies in European patients [39-43] and six studies in American patients $[16,44-48]$. For all 24 studies, the presence of EBV in cancer cells was assessed by in situ hybridisation for EBV-encoded RNA (EBER), the gold standard assay for detecting latent infection. Though a part of excluded studies used other methods for the detection of $E B V$, for example polymerase chain reaction-enzyme immunoassay (PCR-EIA) [49], no studies were excluded just because of inappropriate detection method. With the exclusion of 3 studies that didn't provide follow-up data $[31,44,48]$, the estimated median follow-up time was 3.9 years. The total number of included patients was 8,336 , ranging from 87 [41, 42] to 1,114 [32] patients per study. Table 1 summarizes characteristics of all inclusive studies.

\section{Quality assessment and publication bias}

The range of quality scores was from five to nine stars and the median quality score was seven. We defined the quality score as more than six to indicate a high quality study (see Additional file 2: Table S2). As shown in
Table 1, 21 of 24 quality scores were categorized as high quality studies. The other three studies were categorized as low quality studies [37, 42, 47].

\section{Overall analysis}

The main results of this meta-analysis and the heterogeneity test are presented in Table 2. Among the 24 studies eligible for the meta-analysis, 15 studies reported HRs and $95 \%$ CIs [19, 28, 30-38, 41-43, 46, 47], three provided an RR and $95 \%$ CI $[16,39,48]$, two provided survival curves $[34,40]$ and four provided sufficient data to estimate the HR and $95 \%$ CI [17, 29, 44, 45]. Figure 2 shows the forest plot of the effect sizes and $95 \%$ CIs for each study and the overall value. The pooled HR for OS in GC patients was 0.67 (95\% CI: $0.55-0.79 ; \mathrm{Z}=11.18$, $P<0.001)$ with a fixed-effects model. There was no significant evidence of heterogeneity across studies $\left(\mathrm{I}^{2}=12.8 \%, \mathrm{P}_{\mathrm{Q}}=0.283\right)$. Investigation of publication bias by a funnel plot showed funnel plots was a slight lean (Fig. 3), but the judgments were subjective in nature. The Begg's test $(P=0.655)$ and Egger's test $(P=0.853)$ were 
Table 1 Characteristics of individual studies included in the meta-analysis

\begin{tabular}{|c|c|c|c|c|c|c|}
\hline Study & Region & Year & EBV-positive/EBV-negative & Statistical methodology & HR estimation & Study quality score \\
\hline Gonzalez CA & Europe & 2003 & $4 / 83$ & UA & $\mathrm{HR}+95 \% \mathrm{Cl}$ & $6 / 9$ \\
\hline Chow WH & Europe & 1999 & $11 / 76$ & UA & $\mathrm{HR}+95 \% \mathrm{Cl}$ & $5 / 9$ \\
\hline Kim RH & Asia & 2010 & $18 / 229$ & UA & $\mathrm{HR}+95 \% \mathrm{Cl}$ & $9 / 9$ \\
\hline Gulley ML & Americas & 1996 & $11 / 84$ & UA & $\mathrm{HR}+95 \% \mathrm{Cl}$ & $8 / 9$ \\
\hline Corvalán A & Americas & 2005 & $22 / 71$ & UA & $\mathrm{HR}+95 \% \mathrm{Cl}$ & $9 / 9$ \\
\hline van Beek J & Europe & 2004 & $41 / 525$ & UA & survival curves & $8 / 9$ \\
\hline $\mathrm{He} Y$ & Asia & 2012 & $21 / 97$ & UA & $\mathrm{HR}+95 \% \mathrm{Cl}$ & $7 / 9$ \\
\hline Herrera-Goepfert R & Americas & 2005 & $8 / 127$ & UA & $\mathrm{HR}+95 \% \mathrm{Cl}$ & $5 / 9$ \\
\hline Corvalan A & Americas & 2001 & $27 / 118$ & UA & $\mathrm{HR}+95 \% \mathrm{Cl}$ & $6 / 9$ \\
\hline Koriyama C & Asia & 2007 & $49 / 100$ & UA & $\mathrm{HR}+95 \% \mathrm{Cl}$ & $8 / 9$ \\
\hline Boysen T & Europe & 2011 & $18 / 168$ & UA & $\mathrm{HR}+95 \% \mathrm{Cl}$ & $7 / 9$ \\
\hline Nakao M & Asia & 2011 & $20 / 351$ & UA & $\mathrm{HR}+95 \% \mathrm{Cl}$ & $5 / 9$ \\
\hline Sukawa Y & Asia & 2012 & $18 / 204$ & UA & $\mathrm{HR}+95 \% \mathrm{Cl}$ & $7 / 9$ \\
\hline Chiaravalli AM & Europe & 2006 & $18 / 78$ & UA & $\mathrm{RR}+95 \% \mathrm{Cl}$ & $7 / 9$ \\
\hline Gao Y & Asia & 2009 & $21 / 1018$ & UA & $\mathrm{HR}+95 \% \mathrm{Cl}$ & $7 / 9$ \\
\hline Kijima Y & Asia & 2003 & $25 / 334$ & UA & $\mathrm{HR}+95 \% \mathrm{Cl}$ & $9 / 9$ \\
\hline Koriyama C & Asia & 2002 & $64 / 128$ & MA & $\mathrm{HR}+95 \% \mathrm{Cl}$ & $6 / 9$ \\
\hline Park ES & Asia & 2009 & $50 / 407$ & MA & $\mathrm{HR}+95 \% \mathrm{Cl}$ & $7 / 9$ \\
\hline Song HJ & Asia & 2010 & $123 / 405$ & UA & $\mathrm{HR}+95 \% \mathrm{Cl}$ & $8 / 9$ \\
\hline Grogg KL & Americas & 2003 & $7 / 103$ & UA & $\mathrm{RR}+95 \% \mathrm{Cl}$ & $9 / 9$ \\
\hline Zhao J & Asia & 2012 & $80 / 631$ & UA & survival curves & $7 / 9$ \\
\hline Huang SC & Asia & 2014 & $51 / 943$ & UA & $\mathrm{HR}+95 \% \mathrm{Cl}$ & $8 / 9$ \\
\hline Lee HS & Asia & 2004 & $63 / 1051$ & UA & $\mathrm{HR}+95 \% \mathrm{Cl}$ & $7 / 9$ \\
\hline Truong CD & Americas & 2009 & $12 / 223$ & MA & $\mathrm{RR}+95 \% \mathrm{Cl}$ & $8 / 9$ \\
\hline
\end{tabular}

Abbreviations: EBV Epstein-Barr Virus, $H R$ hazard ratio, $\mathrm{Cl}$ confidence interval, $U A$ univariate analysis, $M A$ multivariate analysis

Table 2 The prognostic significance of Epstein-Barr virus infection in gastric cancer by prespecified study characteristics in different subgroups

\begin{tabular}{|c|c|c|c|c|c|c|c|c|}
\hline \multirow[t]{2}{*}{ Stratified analysis } & \multirow[t]{2}{*}{ No. of Studies } & \multirow{2}{*}{$\begin{array}{l}\text { Test of association } \\
\text { Pooled HR (95\% Cl) }\end{array}$} & \multirow[b]{2}{*}{ Z } & \multirow[b]{2}{*}{ P-value } & \multirow[b]{2}{*}{ Model } & \multicolumn{3}{|c|}{ Test of heterogeneity } \\
\hline & & & & & & $\overline{x^{2}}$ & P-value & $1^{2}(\%)$ \\
\hline Overall & 24 & $0.67(0.55,0.79)$ & 11.18 & $<0.001$ & fixed-effects model & 26.39 & 0.283 & 12.8 \\
\hline \multicolumn{9}{|l|}{ Region } \\
\hline Asia & 13 & $0.62(0.48,0.75)$ & 9.18 & $<0.001$ & fixed-effects model & 19.65 & 0.074 & 38.9 \\
\hline Europe & 5 & $0.87(0.52,1.23)$ & 4.87 & $<0.001$ & fixed-effects model & 1.37 & 0.85 & 0 \\
\hline Americas & 6 & $0.93(0.53,1.34)$ & 4.53 & $<0.001$ & fixed-effects model & 1.76 & 0.881 & 0 \\
\hline \multicolumn{9}{|l|}{ Statistical methodology } \\
\hline Univariate analysis & 21 & $0.62(0.50,0.74)$ & 9.81 & $<0.001$ & fixed-effects model & 18.52 & 0.553 & 0 \\
\hline Multivariate analysis & 3 & $1.13(0.76,1.50)$ & 5.95 & $<0.001$ & fixed-effects model & 1.36 & 0.506 & 0 \\
\hline \multicolumn{9}{|l|}{ Quality assessment } \\
\hline High quality & 21 & $0.67(0.55,0.79)$ & 10.93 & $<0.001$ & fixed-effects model & 25.77 & 0.174 & 22.4 \\
\hline Low quality & 3 & $0.83(0.16,1.51)$ & 2.41 & 0.016 & fixed-effects model & 0.4 & 0.819 & 0 \\
\hline
\end{tabular}

Abbreviations: EBV Epstein - Barr virus, $H R$ hazard ratio, $\mathrm{Cl}$ confidence interval 


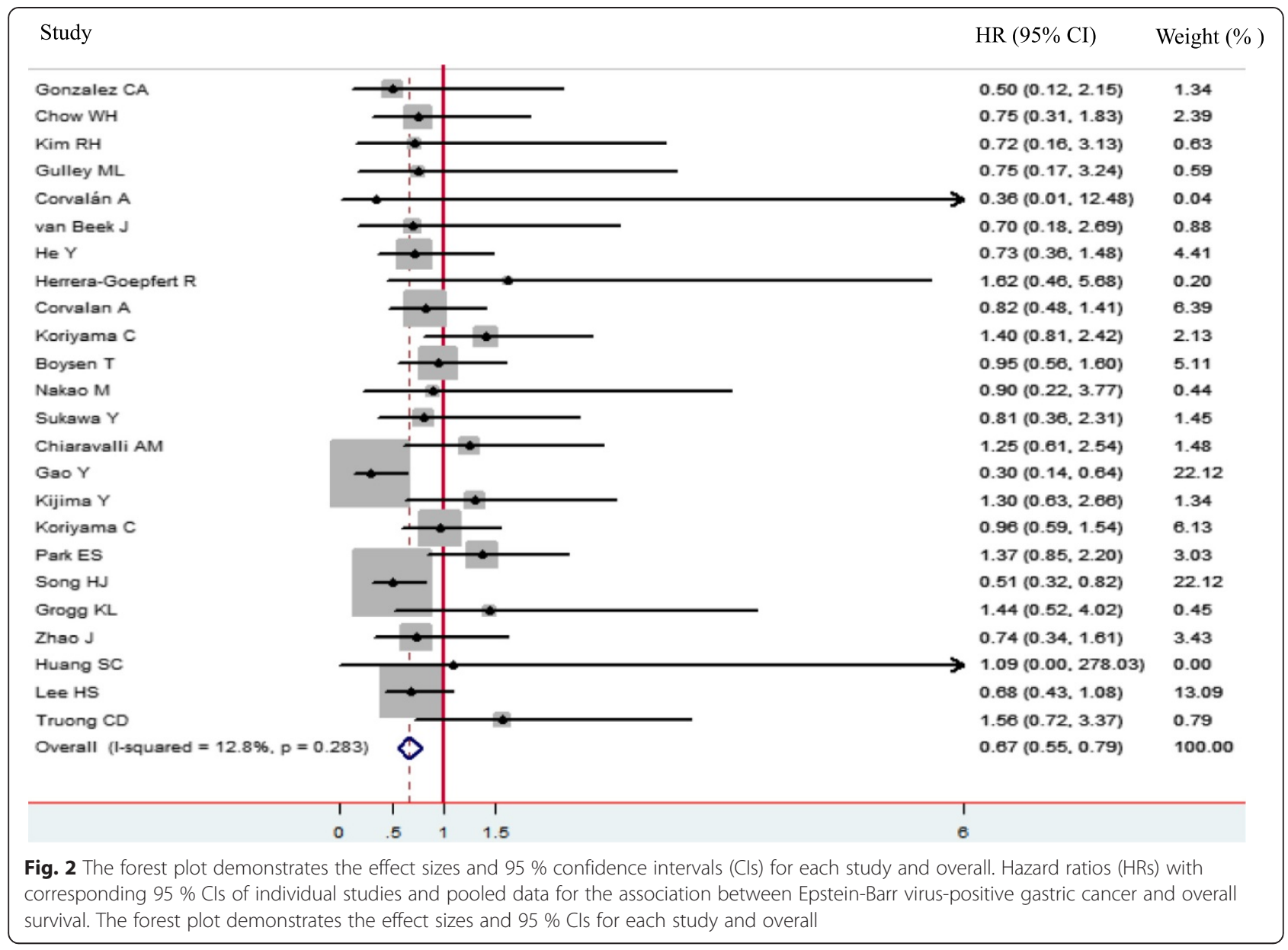

used to further examine asymmetry of the funnel plot (Fig. 4). The P values of both tests were $>0.05$ respectively, which suggested no evidence of publication bias.

\section{Subgroup and sensitivity analyses}

Subgroup analyses were further performed to evaluate the effect of EBV infection on OS in GC patients more comprehensively, and there was no statistically significant heterogeneity or publication bias for all subgroup analyses. The concrete results were as follows: 1) When we stratified the studies by region, the pooled $\mathrm{HR}$ in Asia was 0.62 (95 \% CI: $0.48-0.75 ; P<0.001)$, the pooled HR in Europe was 0.87 (95 \% CI: 0.52-1.23; $P<0.001$ ), and in Americas 0.93 (95\% CI: 0.53-1.34; $P<0.001$ ). After including three low-quality studies, the results of this subgroup analysis were similar (data not shown). 2) When stratified by study quality, the pooled HR for 21 high-quality studies was 0.67 (95 \% CI: 0.55-0.79; $P<0.001)$ and the pooled HR for three low-quality studies was 0.83 (95 \% CI: $0.16-1.51 ; P=0.016)$. 3) When further stratified by statistical methodology (univariate analysis results versus multivariate analysis results), the pooled HR for the univariate analysis results was 0.62

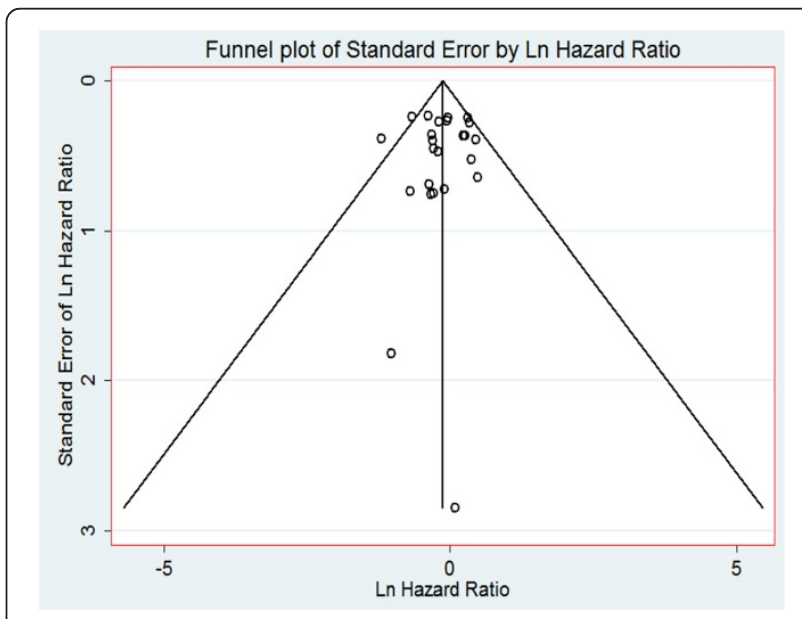

Fig. 3 Funnel Plots for Studies. Funnel plots showing the relationship between the effect size of individual studies (standard error, horizontal axis) and the precision of the study estimate (hazard ratios for overall survival, vertical axis) for EBV 


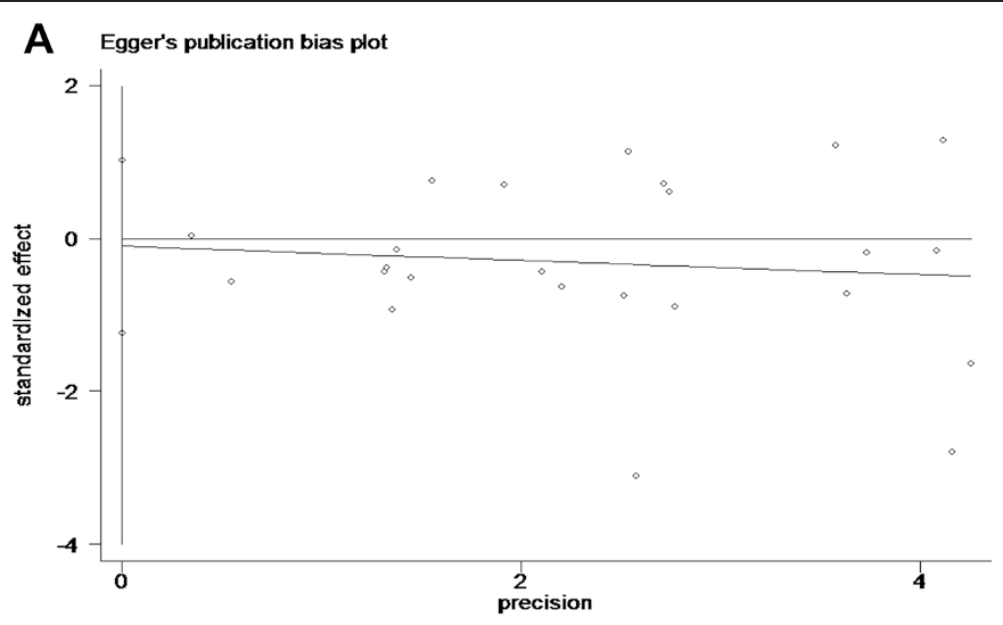

B

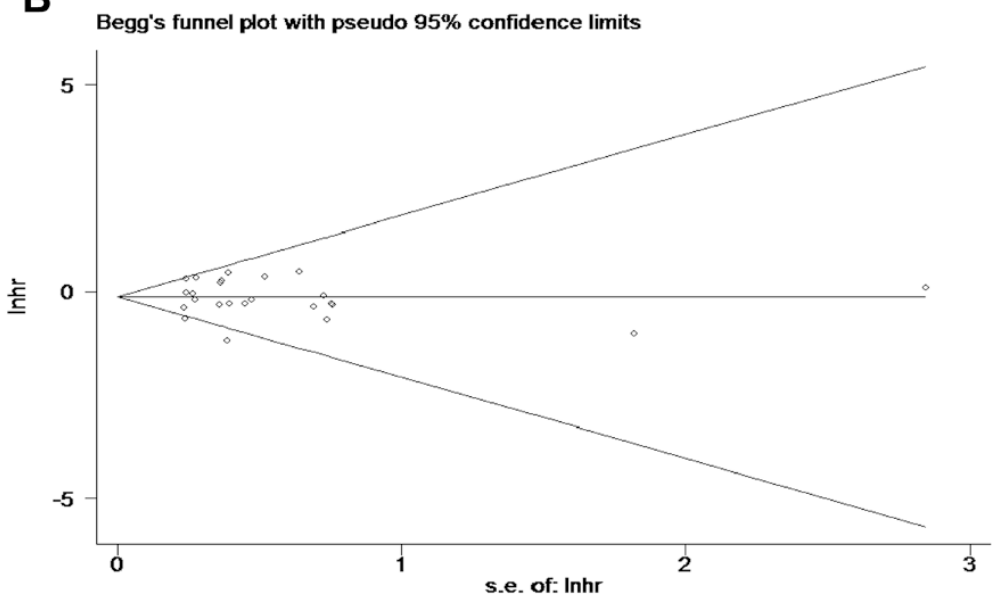

Fig. 4 Publication bias plot for overall survival (a) Egger's publication bias plot (b) Begg's funnel plot

(95 \% CI: 0.50-0.74; $P<0.001$ ). However, the pooled HR for the multivariate analysis results was 1.13 (95\% CI: $0.76-1.50 ; \quad P<0.001)$, with no statistically significant differences.

Sensitivity analyses were carried out to determine if modification of the inclusion criteria for this metaanalysis affected the final results. First, sensitivity analyses to examine the influence of the individual data set to the pooled HR were performed by removing any one study individually and recalculating the pooled HR. The overall pooled HR and $95 \%$ CI were not affected by a single study (data not shown), and the rang was from a low of 0.65 (95\% CI: $0.53-0.77 ; P<0.001$ ) to a high of 0.78 (95 \% CI: $0.64-0.91 ; P<0.001$ ) via omission of the study by Park et al. [30] and the study by Gao et al. [35], respectively. Secondly, sensitivity analyses excluding data from the three studies only providing an RR and $95 \%$ CI did not change the pooled HR (HR: 0.65; $95 \% \mathrm{CI}$ : 0.53-0.77; $P<0.001)$. Lastly, sensitivity analyses excluding the studies of which the HRs (95\% CI) were estimated from the survival curves did not alter the associations (HR: 0.67; 95 \% CI: 0.55-0.79; $P<0.001$ ).

\section{Discussion}

In this study, we first overcame limits of size and region and showed that the presence of EBV has a favorable impact on GC patient survival.

Camargo $\mathrm{MC}$ et al. conducted a pooled analysis including 4,599 patients with GC from 13 studies in 2013. They found EBVaGC had a relative survival advantage [20]. The result was consistent with our study. However, there are some differences between these two studies. First, with the reports of new large sample studies, it is necessary to combine results to reach a more reliable conclusion. For example, a recent study including 994 stage I-III GC patients showed that the OS of EBVpositive patients with GC did not differ from that of EBV-negative patients [17]. He Y et al. also reported a similar conclusion [19]. In the current study, we included these new studies and had the largest cases 
series, a total of 8,336 patients with GC from 24 studies to explore the association to date. Second, in subgroup analysis, the conclusion of the subgroup analysis stratified by region was different [20]. There was an association between EBV infection and better survival in Asian patients. It was worth noting that, the protective role of EBV infection in European and American patients was not observed even after excluding low quality studies. However, Camargo MC et al. found that a survival advantage for EBVaGC was detected in Asia and Europe rather than Americas. Considering the limited number of European case series in the pooled analysis, we suggest our meta-analysis overcame limits of size and region to drive a more reliable conclusion. To date, the underlying reasons for these regional differences are still undefined. However, population differences in genetic factors may help explain part of the regional differences [50]. Studies have reported that EBVaGC displayed distinct clinical and genetic features. In EBVaGC, the prevalent types and variants of EBV in eastern countries were different from those in Latin American countries, suggesting that some EBV sequence variations might be geographically distributed $[51,52]$. In addition, we speculated that there might be difference in the way of diagnosis and treatment between Asian and Western countries, though we didn't find sufficient information from included studies. By now, the treament for GC is still ignored of the EBV status [53]. However, several promising therapeutic approaches are worthwhile to be further explored. A recent study from Hui KF et al. demonstrated that, the FDA (Food and Drug Administration)-approved Pan-histone deacetylase (HDAC) inhibitor romidepsin, which could potently induce EBV lytic cycle and mediate enhanced cell death with ganciclovir (GCV), might be applied for the treatment of EBVaGC [54]. Moreover, medical treatment with a demethylation agent may have particular merit in the therapy of EBVaGC, since methylation of the tumor suppressor gene is also a key abnormality in EBVaGC. Other potential medical treatment, such as proteosome inhibitor, antiviral drugs, inhibition of EBV-induced oncogenic cellular signaling pathways and EBV vaccines, may have an important role in the therapy of EBVaGC $[11,55]$. Therefore, it is of interest whether difference in the way of treatment between Asian and Western countries impacts survival.

Furthermore, stratified subgroup analyses were performed by study quality and statistical methodology. We found the protective role of EBV infection in GC remained statistically significant in high quality studies and in univariate analysis results. However, the results of the multivariate analysis limited our conclusions. Considering that there has been only three multivariate analyses, our analysis should be viewed with caution.

Our meta-analysis found that patients with EBVaGC have a significantly better outcome than those with
EBV-negative GC. Though many studies have been conducted to explore this phenomenon, the mechanisms underlying better outcomes of EBVaGC are still ambiguous, by far. Most cases of EBVaGC exhibit a histology rich in lymphocyte infiltration $[39,56]$, which may represent a relatively preferable prognosis in EBVaGC cases because of the improved anti-tumor immune response. In addition, genetic alteration and methylation of the tumor suppressor gene may be another key mechanism $[57,58]$. It may be possible that, as reported in EBV-positive nasopharyngeal carcinoma, EBVaGC has a better prognosis in part because of better response to therapy [59, 60]. Further studies are needed to identify the mechanisms underlying this prognostic association.

Although we comprehensively evaluated the association between EBV and prognosis in GC with reasonable statistical methods, several limitations of the current meta-analysis should be addressed. First, we only explored the effect of EBV infection on OS in GC patients, and other factors that may contribute to the tumorigenesis of GC, such as genetic factors, environmental exposures and hereditary factors, were not considered. It is necessary to clarify the interactions between these factors and EBV infection in further studies. Secondly, it is difficult to acquire original data to remove other possible confounding factors, such as less p53 abnormal expression, higher expression of Human Interleukin 1 Beta (IL-1b) and so on. Thirdly, as we all know, the publicly accepted TNM system (7th UICC) is the gold standard to evaluate GC prognosis. In addition, it has been accepted that EBVaGC is typically located in non-antral subsites [11]. We are aware of the fact that differences in tumor location may impact survival, but the paucity of individual-level data on variables limits further study. Thus, our conclusion needs to be verified by studies of multivariate analysis adjusting for clinicopathological variables.

\section{Conclusions}

To our knowledge, this study has the largest case series by far to explore the potential role of EBV in GC. We found that EBV infection has a favorable impact on GC patient survival, especially in the Asian population. Future studies, especially large-scale randomized controlled studies stratified by region, taking into account the classical well defined prognostic factors, are warranted as validation studies.

\section{Additional files}

Additional file 1: Table S1. Newcastle-Ottawa Quality Assessment Scale. (PDF $36 \mathrm{~kb}$ )

Additional file 2: Table S2. PRISMA 2009 checklist in current meta-analysis. (DOC 70 kb) 


\section{Abbreviations}

EBV: Epstein-Barr virus; GC: Gastric cancer; HR: Hazard ratio; Cl: Confidence interval; EBVaGC: EBV-associated gastric carcinoma; LELC: ILymphoepitheliomalike carcinoma; MeSH: Medical Subject Headings; OS: Overall survival; NOS: Newcastle-Ottawa Scale; PRISMA: Preferred Reporting Items for Systematic Reviews and Meta-Analyses; RR: Risk ratio; EBER: EBV-encoded RNA; PCREIA: Polymerase chain reaction-enzyme immunoassay; FDA: Food and Drug Administration; HDAC: Histone deacetylase; GCV: Ganciclovir; IL-1b: Human Interleukin 1 Beta.

\section{Competing interests}

The authors declare that they have no competing interests.

\section{Authors' contributions}

LXC and $\amalg J$ contributed equally to this work, SXW and XDZ contributed to the conception and design of the study; LXC, LJ, CSX and KPF performed literature search, data extraction, quality assessment and statistical analyses; LXC composed the first draft of the manuscript; QHB, LW, LYF, CYB, ZZW and ZYQ read and critically revised the manuscript. All authors have read and approved the final manuscript.

\section{Acknowledgments}

We thank all the people who give the help for this study.

\section{Author details}

'State Key Laboratory of Oncology in South China, Collaborative Innovation Center for Cancer Medicine, Guangzhou, China. ${ }^{2}$ Department of Gastric and Pancreatic Surgery, Sun Yat-sen University Cancer Center, 651\# East Dongfeng Road, Guangzhou 510000, Guangdong Province, China.

\section{Received: 21 January 2015 Accepted: 16 October 2015} Published online: 24 October 2015

\section{References}

1. Hamashima C. Current issues and future perspectives of gastric cancer screening. World J Gastroenterol. 2014;20(38):13767-74.

2. Camargo MC, Murphy G, Koriyama C, Pfeiffer RM, Kim WH, Herrera-Goepfert $R$, et al. Determinants of Epstein-Barr virus-positive gastric cancer: an international pooled analysis. Br J Cancer. 2011;105(1):38-43.

3. Pasechnikov V, Chukov S, Fedorov E, Kikuste I, Leja M. Gastric cancer: prevention, screening and early diagnosis. World J Gastroenterol. 2014:20(38):13842-62.

4. Selves J, Bibeau F, Brousset P, Meggetto F, Mazerolles C, Voigt JJ, et al. Epstein-Barr virus latent and replicative gene expression in gastric carcinoma. Histopathology. 1996;28(2):121-7.

5. Yuen ST, Chung LP, Leung SY, Luk IS, Chan SY, Ho J. In situ detection of Epstein-Barr virus in gastric and colorectal adenocarcinomas. Am J Surg Pathol. 1994;18(11):1158-63.

6. Shibata D, Tokunaga M, Uemura Y, Sato E, Tanaka S, Weiss LM. Association of Epstein-Barr virus with undifferentiated gastric carcinomas with intense lymphoid infiltration. Lymphoepithelioma-like carcinoma. Am J Pathol. 1991;139(3):469-74.

7. Young LS, Rickinson AB. Epstein-Barr virus: 40 years on. Nat Rev Cancer. 2004;4(10):757-68.

8. Zong L, Seto Y. CpG island methylator phenotype, Helicobacter pylori, Epstein-Barr virus, and microsatellite instability and prognosis in gastric cancer: a systematic review and meta-analysis. PLoS One. 2014;9(1):e86097.

9. Rowe M, Fitzsimmons L, Bell Al. Epstein-Barr virus and Burkitt lymphoma. Chin J Cancer. 2014:33(12):609-19.

10. Maeda E, Akahane M, Kiryu S, Kato N, Yoshikawa T, Hayashi N, et al. Spectrum of Epstein-Barr virus-related diseases: a pictorial review. Jpn J Radiol. 2009;27(1):4-19.

11. Chen JN, He D, Tang F, Shao CK. Epstein-Barr virus-associated gastric carcinoma: a newly defined entity. J Clin Gastroenterol. 2012;46(4):262-71.

12. Lee JH, Kim SH, Han SH, An JS, Lee ES, Kim YS. Clinicopathological and molecular characteristics of Epstein-Barr virus-associated gastric carcinoma: a meta-analysis. J Gastroenterol Hepatol. 2009;24(3):354-65.

13. Li S, Du H, Wang Z, Zhou L, Zhao X, Zeng Y. Meta-analysis of the relationship between Epstein-Barr virus infection and clinicopathological features of patients with gastric carcinoma. Sci China Life Sci. 2010;53(4):524-30
14. Burgess DE, Woodman CB, Flavell KJ, Rowlands DC, Crocker J, Scott K, et al. Low prevalence of Epstein-Barr virus in incident gastric adenocarcinomas from the United Kingdom. Br J Cancer. 2002;86(5):702-4.

15. Cheng N, Hui DY, Liu Y, Zhang NN, Jiang Y, Han J, et al. Is gastric lymphoepithelioma-like carcinoma a special subtype of EBV-associated gastric carcinoma? New insight based on clinicopathological features and EBV genome polymorphisms. Gastric Cancer. 2015;18(2):246-55.

16. Grogg KL, Lohse CM, Pankratz VS, Halling KC, Smyrk TC. Lymphocyte-rich gastric cancer: associations with Epstein-Barr virus, microsatellite instability, histology, and survival. Modern Pathol. 2003;16(7):641-51.

17. Huang SC, Ng KF, Chen KH, Hsu JT, Liu KH, Yeh TS, et al. Prognostic factors in Epstein-Barr virus-associated stage I-III gastric carcinoma: implications for a unique type of carcinogenesis. Oncol Rep. 2014;32(2):530-8.

18. Genitsch V, Novotny A, Seiler CA, Kroll D, Walch A, Langer R: Epstein-barr virus in gastro-esophageal adenocarcinomas - single center experiences in the context of current literature. Frontiers in oncology. 2015;5:73.

19. He Y, Zhao X, Gao J, Fan L, Yang G, Cho WC, et al. Quantum dots-based immunofluorescent imaging of stromal fibroblasts Caveolin-1 and light chain 3B expression and identification of their clinical significance in human gastric cancer. Int J Mol Sci. 2012;13(11):13764-80.

20. Camargo MC, Kim WH, Chiaravalli AM, Kim KM, Corvalan AH, Matsuo K, et al. Improved survival of gastric cancer with tumour Epstein-Barr virus positivity: an international pooled analysis. Gut. 2014;63(2):236-43.

21. Royston $P$, Parmar MK. Restricted mean survival time: an alternative to the hazard ratio for the design and analysis of randomized trials with a time-to-event outcome. BMC Med Res Methodol. 2013;13:152

22. Parmar MK, Torri $V$, Stewart L. Extracting summary statistics to perform meta-analyses of the published literature for survival endpoints. Stat Med. 1998;17(24):2815-34.

23. Moher D, Liberati A, Tetzlaff J, Altman DG. Reprint-preferred reporting items for systematic reviews and meta-analyses: the PRISMA statement. Phys Ther. 2009:89(9):873-80.

24. Panic N, Leoncini E, de Belvis G, Ricciardi W, Boccia S. Evaluation of the endorsement of the preferred reporting items for systematic reviews and meta-analysis (PRISMA) statement on the quality of published systematic review and meta-analyses. PLoS One. 2013;8(12):e83138.

25. Higgins JP, Thompson SG. Quantifying heterogeneity in a meta-analysis. Stat Med. 2002;21(11):1539-58.

26. Egger M, Smith GD. Bias in location and selection of studies. BMJ (Clinical Re ed). 1998;316(7124):61-6.

27. Tokunaga M, Uemura $Y$, Tokudome $T$, Ishidate $T$, Masuda H, Okazaki E, et al. Epstein-Barr virus related gastric cancer in Japan: a molecular pathoepidemiological study. Acta Pathol Jpn. 1993;43(10):574-81.

28. Sukawa $Y$, Yamamoto $H$, Nosho $K$, Kunimoto $H$, Suzuki $H$, Adachi $Y$, et al. Alterations in the human epidermal growth factor receptor 2phosphatidylinositol 3-kinase-v-Akt pathway in gastric cancer. World J Gastroenterol. 2012;18(45):6577-86.

29. Song HJ, Srivastava A, Lee J, Kim YS, Kim KM, Ki Kang W, et al. Host inflammatory response predicts survival of patients with Epstein-Barr virus-associated gastric carcinoma. Gastroenterology. 2010;139(1):84-92:e82

30. Park ES, Do IG, Park CK, Kang WK, Noh JH, Sohn TS, et al. Cyclooxygenase-2 is an independent prognostic factor in gastric carcinoma patients receiving adjuvant chemotherapy and is not associated with EBV infection. Clinical Cancer Res. 2009;15(1):291-8

31. Koriyama C, Akiba S, Itoh T, Sueyoshi K, Minakami Y, Corvalan A, et al. E-cadherin and beta-catenin expression in Epstein-Barr virus-associated gastric carcinoma and their prognostic significance. World J Gastroenterol. 2007:13(29):3925-31.

32. Lee HS, Chang MS, Yang HK, Lee BL, Kim WH. Epstein-barr virus-positive gastric carcinoma has a distinct protein expression profile in comparison with epstein-barr virus-negative carcinoma. Clinical Cancer Res. 2004;10(5):1698-705.

33. Kijima Y, Ishigami S, Hokita S, Koriyama C, Akiba S, Eizuru Y, et al. The comparison of the prognosis between Epstein-Barr virus (EBV)-positive gastric carcinomas and EBV-negative ones. Cancer Lett. 2003;200(1):33-40.

34. Zhao J, Jin H, Cheung KF, Tong JH, Zhang S, Go MY, et al. Zinc finger E-box binding factor 1 plays a central role in regulating Epstein-Barr virus (EBV) latent-lytic switch and acts as a therapeutic target in EBV-associated gastric cancer. Cancer. 2012;118(4):924-36.

35. Gao Y, Hu N, Han X, Giffen C, Ding T, Goldstein A, et al. Family history of cancer and risk for esophageal and gastric cancer in Shanxi China. BMC Cancer. 2009;9:269. 
36. Koriyama C, Akiba S, Itoh T, Kijima Y, Sueyoshi K, Corvalan A, et al. Prognostic significance of Epstein-Barr virus involvement in gastric carcinoma in Japan. Int J Mol Med. 2002;10(5):635-9.

37. Nakao M, Matsuo K, Ito H, Shitara K, Hosono S, Watanabe M, et al. ABO genotype and the risk of gastric cancer, atrophic gastritis, and Helicobacter pylori infection. Cancer Epidemiol Biomarkers Prevention. 2011;20(8):1665-72.

38. Kim RH, Chang MS, Kim HJ, Song KS, Kim YS, Choi BY, et al. Medical history and lifestyle factors contributing to Epstein-Barr virus-associated gastric carcinoma and conventional gastric carcinoma in Korea. Anticancer Res. 2010;30(6):2469-75.

39. Chiaravalli AM, Feltri M, Bertolini V, Bagnoli E, Furlan D, Cerutti R, et al. Intratumour T cells, their activation status and survival in gastric carcinomas characterised for microsatellite instability and Epstein-Barr virus infection. Virchows Archiv. 2006;448(3):344-53.

40. Van Beek J, Zur Hausen A, Klein Kranenbarg E, Van de Velde CJ, Middeldorp JM, Van Den Brule AJ, et al. EBV-positive gastric adenocarcinomas: a distinct clinicopathologic entity with a low frequency of lymph node involvement. J Clinical Oncol. 2004;22(4):664-70.

41. Gonzalez CA, Pera G, Agudo A, Palli D, Krogh V, Vineis P, et al. Smoking and the risk of gastric cancer in the European Prospective Investigation Into Cancer and Nutrition (EPIC). Int J Cancer. 2003;107(4):629-34.

42. Chow WH, Swanson CA, Lissowska J, Groves FD, Sobin LH, NasierowskaGuttmejer A, et al. Risk of stomach cancer in relation to consumption of cigarettes, alcohol, tea and coffee in Warsaw, Poland. Int J Cancer. 1999;81(6):871-6.

43. Boysen T, Friborg J, Stribolt K, Hamilton-Dutoit S, Goertz S, Wohlfahrt J, et al. Epstein-Barr virus-associated gastric carcinoma among patients with pernicious anemia. Int J Cancer. 2011;129(11):2756-60.

44. Corvalan A, Akiba S, Valenzuela MT, Cumsille MA, Koriyama C, Argandona J, et al. Clinical and molecular features of cardial gastric cancer associated to Epstein Barr virus. Rev Med Chil. 2005;133(7):753-60.

45. Gulley ML, Pulitzer DR, Eagan PA, Schneider BG. Epstein-Barr virus infection is an early event in gastric carcinogenesis and is independent of bcl-2 expression and p53 accumulation. Hum Pathol. 1996;27(1):20-7.

46. Corvalan A, Koriyama C, Akiba S, Eizuru Y, Backhouse C, Palma M, et al. Epstein-Barr virus in gastric carcinoma is associated with location in the cardia and with a diffuse histology: a study in one area of Chile. Int J Cancer. 2001;94(4):527-30.

47. Herrera-Goepfert R, Akiba S, Koriyama C, Ding S, Reyes E, Itoh T, et al. Epstein-Barr virus-associated gastric carcinoma: Evidence of age-dependence among a Mexican population. World J Gastroenterol. 2005;11(39):6096-103.

48. Truong CD, Feng W, Li W, Khoury T, Li Q, Alrawi S, et al. Characteristics of Epstein-Barr virus-associated gastric cancer: a study of 235 cases at a comprehensive cancer center in U.S.A. J Exp Clinical Cancer Res. 2009;28:14.

49. Van Beek J, Zur Hausen A, Kranenbarg EK, Warring RJ, Bloemena E, Craanen $M E$, et al. A rapid and reliable enzyme immunoassay PCR-based screening method to identify EBV-carrying gastric carcinomas. Modern Pathol. 2002;15(8):870-7

50. Nishikawa J, Yoshiyama H, lizasa H, Kanehiro Y, Nakamura M, Nishimura J, et al. Epstein-barr virus in gastric carcinoma. Cancers. 2014;6(4):2259-74.

51. Fukayama M, Hayashi Y, Iwasaki Y, Chong J, Ooba T, Takizawa T, et al. Epstein-Barr virus-associated gastric carcinoma and Epstein-Barr virus infection of the stomach. Laboratory Invest. 1994;71(1):73-81.

52. Corvalan A, Ding S, Koriyama C, Carrascal E, Carrasquilla G, Backhouse C, et al. Association of a distinctive strain of Epstein-Barr virus with gastric cancer. Int J Cancer. 2006;118(7):1736-42.

53. lizasa H, Nanbo A, Nishikawa J, Jinushi M, Yoshiyama H. Epstein-Barr Virus (EBV)-associated gastric carcinoma. Viruses. 2012;4(12):3420-39.

54. Hui KF, Cheung AK, Choi CK, Yeung PL, Middeldorp JM, Lung ML, et al. Inhibition of class I histone deacetylases by romidepsin potently induces Epstein-Barr virus lytic cycle and mediates enhanced cell death with ganciclovir. International journal of cancer Journal international du cancer. 2016;138(1):125-36

55. Neparidze N, Lacy J. Malignancies associated with epstein-barr virus: pathobiology, clinical features, and evolving treatments. Clinical Adv Hematol Oncol. 2014;12(6):358-71.

56. Lee JM, Kim H, Noh SH, Lee WY, Kim SJ, Park JH. Expression of Epstein-Barr Virus Gene and Clonality of Infiltrated T Lymphocytes in Epstein-Barr Virusassociated Gastric Carcinoma. Immune Network. 2011;11(1):50-8.

57. Van Rees BP, Caspers E, Zur Hausen A, Van den Brule A, Drillenburg P, Weterman MA, et al. Different pattern of allelic loss in Epstein-Barr virus- positive gastric cancer with emphasis on the p53 tumor suppressor pathway. Am J Pathol. 2002;161(4):1207-13.

58. Matsusaka K, Kaneda A, Nagae G, Ushiku T, Kikuchi Y, Hino R, et al. Classification of Epstein-Barr virus-positive gastric cancers by definition of DNA methylation epigenotypes. Cancer Res. 2011;71(23):7187-97.

59. Murray PG, Billingham LJ, Hassan HT, Flavell JR, Nelson PN, Scott K, et al. Effect of Epstein-Barr virus infection on response to chemotherapy and survival in Hodgkin's disease. Blood. 1999;94(2):442-7.

60. Basso S, Zecca M, Calafiore L, Rubert L, Fiocchi R, Paulli M, et al. Successful treatment of a classic Hodgkin lymphoma-type post-transplant lymphoproliferative disorder with tailored chemotherapy and Epstein-Barr virus-specific cytotoxic T lymphocytes in a pediatric heart transplant recipient. Pediatr Transplant. 2013;17(7):E168-173.

\section{Submit your next manuscript to BioMed Central and take full advantage of:}

- Convenient online submission

- Thorough peer review

- No space constraints or color figure charges

- Immediate publication on acceptance

- Inclusion in PubMed, CAS, Scopus and Google Scholar

- Research which is freely available for redistribution 